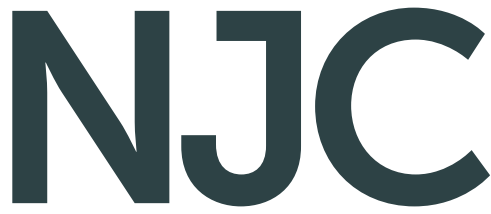

New Journal of Chemistry

A journal for new directions in chemistry www.rsc.org/njc

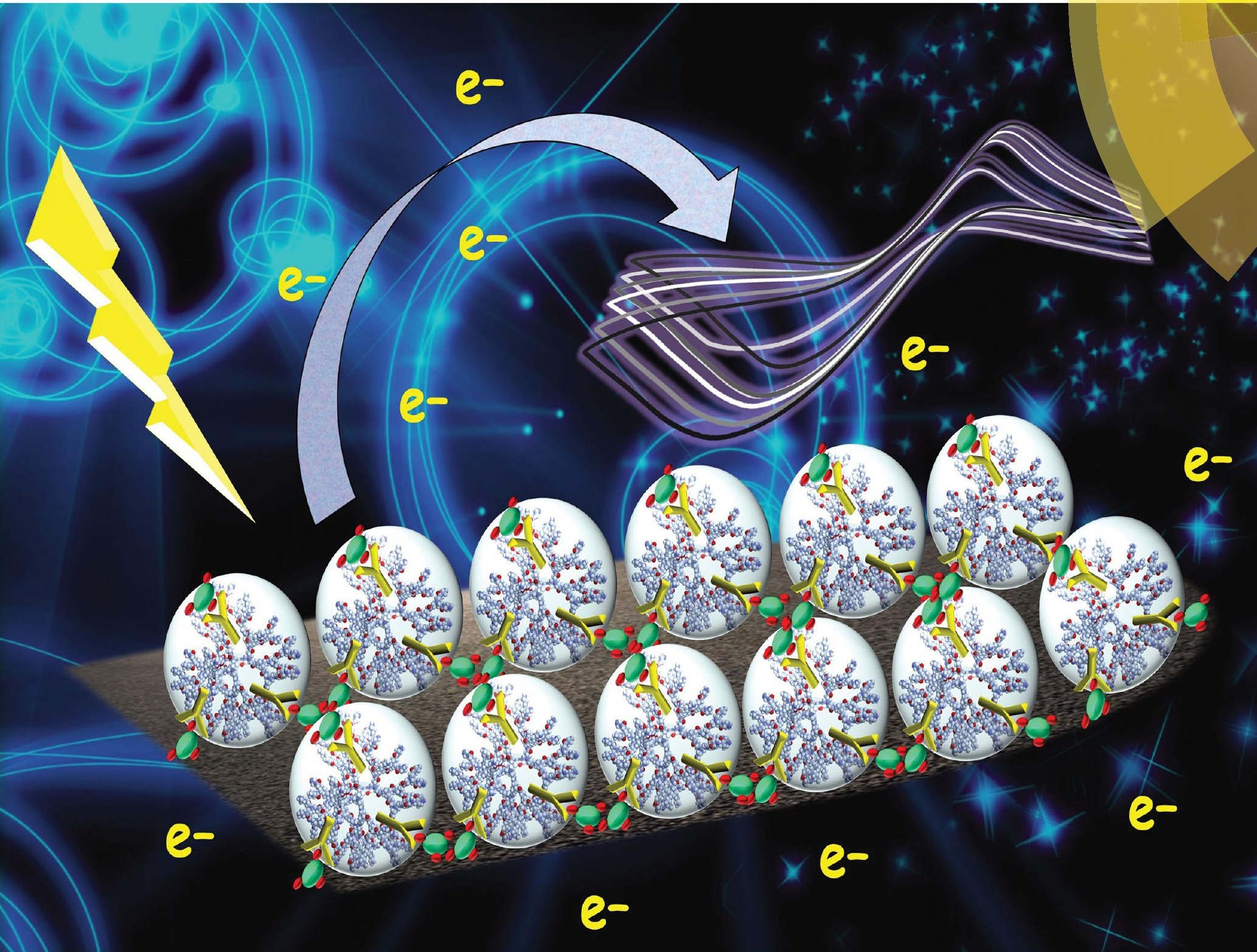

ISSN 1144-0546

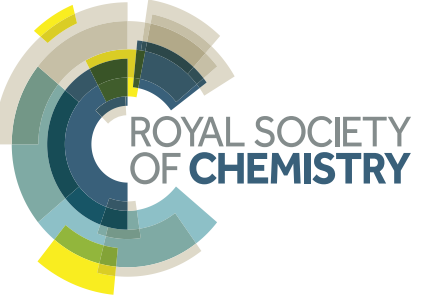




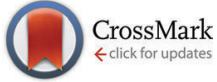

Cite this: New J. Chem., 2016, 40, 9046

\title{
Fabrication of a label-free electrochemical immunosensor using a redox active ferrocenyl dendrimer
}

\author{
Sudeshna Chandra, ${ }^{\text {a }}$ Christian Gäbler, ${ }^{\mathrm{b}}$ Christian Schliebe, ${ }^{\mathrm{b}}$ Heinrich Lang ${ }^{\mathrm{b}}$ and \\ Dhirendra Bahadur
}

We report an IgG (=immunoglobulin) electrochemical immunosensor using a newly synthesized redox-active ferrocenyl dendrimer of generation $2\left(\mathbf{G}_{2} \mathbf{F c}\right)$ as a voltammetric transducer. The ferrocenyl dendrimer $\mathrm{N}\left(\mathrm{CH}_{2} \mathrm{CH}_{2} \mathrm{C}(\mathrm{O}) \mathrm{NHCH}_{2} \mathrm{CH}_{2} \mathrm{NHC}(\mathrm{O}) \mathrm{Fe}\left(\eta^{5}-\mathrm{C}_{5} \mathrm{H}_{4}\right)\left(\eta^{5}-\mathrm{C}_{5} \mathrm{H}_{5}\right)\right)\left(\mathrm{CH}_{2} \mathrm{CH}_{2} \mathrm{~N}\left(\mathrm{CH}_{2} \mathrm{CH}_{2} \mathrm{C}(\mathrm{O}) \mathrm{NHCH}_{2} \mathrm{CH}_{2} \mathrm{NHClO}\right) \mathrm{Fe}\left(\eta^{5}-\right.\right.$ $\left.\left.\left.\mathrm{C}_{5} \mathrm{H}_{4}\right)\left(\eta^{5}-\mathrm{C}_{5} \mathrm{H}_{5}\right)\right)_{2}\right)_{2}\left(\mathrm{G}_{2} \mathrm{Fc}\right)$ was used as a functional moiety to immobilize the antibody on the surface of

Received (in Montpellier, France) 15th March 2016,

Accepted 30th August 2016

DOI: 10.1039/c6nj00830e

www.rsc.org/njc the electrode. A sandwich immunosensor of the type $\lg G /$ Bovine serum albumin (BSA)/anti-lgG/ $\mathrm{G}_{2} \mathrm{Fc} /$ glassy carbon electrode (GCE) was fabricated. The electrochemical properties of $\mathrm{G}_{2} \mathrm{Fc}$ were thoroughly studied in aqueous and non-aqueous electrolytes with varying scan rates. The incubation time was optimized for better analytical performance of the immunosensor. It is found that the developed amperometric immunosensor is sensitive to a concentration of $\lg \mathrm{G}$ as low as $2 \mathrm{ng} \mathrm{mL} \mathrm{L}^{-1}$.

\section{Introduction}

Electro-active dendrimers containing multiple redox units have generated great interest for their use as electrode modifiers for the development of biosensors. ${ }^{1}$ A wide variety of dendrimers have been fabricated with centrally and peripherally located redox-active units. For example, dendrimers functionalized with ferrocenyl end-grafted building blocks and their derivatives have shown promising results. ${ }^{2}$ Ferrocenes are capable of transferring multiple numbers of electrons under the same potential, and therefore, exhibit stable reversible redox properties. In ferrocenyl functionalized dendrimers, the redox centers are usually separated from one another, and therefore, show negligible electrostatic effects. ${ }^{3}$ Recently, it was shown that even for a 14000 ferrocenyl bearing dendrimer, no electrostatic effects were observed. ${ }^{4}$ However, in small rigid dendrimers, there can be some electrostatic effects seen between the ferrocenyl end-grafted moieties due to a short inter-site distance between the terminal groups. ${ }^{5,6}$ In such cases, the cyclic voltammogram wave is fragmented into smaller ones indicating multiple step electron transfer processes. The electron transfer between redox-active dendrimers and a variety of other biomolecules plays a key role

\footnotetext{
${ }^{a}$ Department of Chemistry, Sunandan Divatia School of Science, NMIMS University, Vile Parle (West) Mumbai-400056, India. E-mail: sudeshna.chandra@nmims.edu; Tel: +91 22-42199956

${ }^{b}$ Technische Universität Chemnitz, Faculty of Natural Sciences, Institute of Chemistry, Inorganic Chemistry, 09107 Chemnitz, Germany

${ }^{c}$ Department of Metallurgical Engineering and Material Science,

Indian Institute of Technology Bombay, Mumbai-400076, India
}

in promising applications in, for example, the area of biosensors. $^{7}$

Cancer biomarkers are molecules, generally proteins, that are over-expressed in cancer cells and whose measurement or identification plays an important role in the diagnosis of cancer. ${ }^{8}$ These biomarkers of cancer encompass physical symptoms, mutated DNAs and RNAs, secreted proteins and serum levels. Therefore, the detection of cancer biomarkers at an early stage can provide crucial information for foundational research of life sciences, clinical diagnosis and prevention of disease. Elevated concentration of biomarkers in body fluid is an early indication of some type of cancerous disease and among all the biomarkers, IgG are the most common and extensively used clinical cancer biomarkers for several carcinomas like human cervical, breast, liver, colon and lung cancer. ${ }^{9}$ All these carcinomas produce IgG in both cytoplasmic and secreted forms. The most important goal of a cancer biomarker is the detection of the smallest number of tumor cells in human fluid. ${ }^{8,10}$ Thus, to realize the potentiality of biomarkers in diagnosis, novel bioanalytical techniques must be developed with improved accuracy and sensitivity.

A sandwich immunosensor is a major analytical technique that can be used for the sensitive and selective detection of cancer biomarkers. However, there are only a handful of studies available on this topic. ${ }^{11}$ Electrochemical immunosensors are fabricated by immobilizing the antigen-antibody on the surface of the electrode transducer and the conventional methods are physical adsorption, covalent binding and polymer entrapment. ${ }^{12}$ Qiao et al. ${ }^{13}$ reported a change in the electrochemical signal i.e., 
a decrease in the redox peak intensity upon the adsorption of an antibody on the electrodes due to its non-electrochemical activity which partially blocked the electron transfer between the electrode and $\left[\mathrm{Fe}(\mathrm{CN})_{6}\right]^{3-/ 4}$. After the antigen-antibody reaction, a further decrease of the redox peaks was observed. Thus, there is a change in the electrochemical signal. The analyte is measured through the detection of electrochemical signals produced due to antigen-antibody reactions. ${ }^{13}$ Electrochemical immunosensors are known for fast and sensitive analysis, are inexpensive and involve no prior sample pretreatment. Electrochemical amperometric immunosensors are even more promising because they can achieve a very low detection limit with high sensitivity. Amperometry is gaining attention due to its role in the development of immunosensors and therefore a novel immobilization technique with enhanced sensitivity and selectivity with less response time is of considerable interest. ${ }^{14}$

A number of electroactive materials have been investigated as signaling species like metal nanoparticles and quantum dots. ${ }^{15-18}$ Various electroactive materials, transducer techniques and their response to different cancer biomarkers are summarized in Table 1. An amperometric immune-sensor based on gold nanoparticles was reported by Liang and $\mathrm{Mu}$ in which the nanoparticles were used to modify the electrodes for the determination of paraoxon, a carcinoembryonic antigen and interleukin-6. ${ }^{19} \mathrm{Wu}$ et $a .^{20}$ reported on the use of electrochemical biosensors based on gold nanoparticles/polylactide nanocomposites for sensitive recognition of leukemia K562 cells.

Among various signaling species, ${ }^{23}$ dendrimers are recognized as promising candidates for bioconjugation for the construction of electrochemical biosensors. ${ }^{24}$ Highly branched dendrimers provide structural homogeneity, controlled composition, comparable size to biomolecules, internal porosity and multiple functional groups for conjugation reactions. ${ }^{25}$ Further, the endgrafted groups can be synthetically manipulated for obtaining a desired structure according to the functional requirement. To this end, the surface of polyamidoamine (PAMAM)-dendrimers can be modified with redox-active ferrocenyl building blocks to obtain well-structured end-grafted ferrocenyl dendrimers that can be used as signaling species for fabricating electrochemical biosensors. ${ }^{24}$ The ferrocenyl units are multiple and electrochemically equivalent redox units and can act as an electron "pool", and both Fe(II) and Fe(III) forms are stable on the electrochemical time scale. The ferrocenyl-terminated PAMAM
(Fc) dendrimer is capable of transferring multiple numbers of electrons under the same applied potential. In this way, redoxactive dendrimers can be used for dual purposes: one for building a film over the electrode and the other for immobilizing biomolecules for sensing. ${ }^{25}$

Herein, a novel electrochemical immunosensor for the detection of cancer biomarkers is proposed, which is based on a redox-active ferrocenyl dendrimer on a glassy carbon electrode (GCE). The electrochemical response by cyclic voltammetry (CV) has been used to detect over-expressed immunoglobulin (IgG) in the presence of a specific probe. The CV measurements were used to characterize each step of surface modification resulting due to the binding of IgG to anti-IgG. The change in voltammetric response, due to the formation of an immune complex produced by the antibody-antigen reaction was used for the sensitive detection of cancer biomarkers by amperometry. ${ }^{14}$ The reported detection technique is simple, convenient, reproducible and sensitive. The redox active $\mathbf{G}_{\mathbf{2}} \mathbf{F c}$ showed promising results in the recognition of cancer biomarkers at a very low concentration and at an early stage (Scheme 1).

\section{Experimental}

\section{Materials and instruments}

All reactions were carried out under a nitrogen or argon atmosphere using standard Schlenk techniques. Dichloromethane was used from a MBRAUN (MB-SPS 800) solvent drying and purification system. As starting materials, the $\mathrm{H}_{2} \mathrm{~N}$ end-grafted dendrimer $(\mathbf{1})^{26}$ and ferrocene carboxylic acid fluoride $(2)^{27}$ were prepared according to the published procedures. ${ }^{28}$ All other reagents were used as received from commercial suppliers. The NMR spectrum was recorded using a Bruker Avance III 500 spectrometer. The ${ }^{1} \mathrm{H}$ NMR spectrum was recorded at 500.3 MHz and the ${ }^{13} \mathrm{C}\left\{{ }^{1} \mathrm{H}\right\}$ one at $125.7 \mathrm{MHz}$, respectively. Chemical shifts are reported in $\delta$ units (parts per million) downfield from tetramethylsilane with the solvent as a reference signal $\left({ }^{1} \mathrm{H}\right.$ NMR: standard internal $\mathrm{CDCl}_{3}, \delta 7.26 ;{ }^{13} \mathrm{C}\left\{{ }^{1} \mathrm{H}\right\}$ NMR: standard internal $\mathrm{CDCl}_{3}, \delta$ 77.16). High resolution mass spectra were recorded using a Bruker Daltonik micrOTOF-QII spectrometer (ESI-TOF). Elemental analysis was carried out using a Thermo Flash AE 1112 series instrument.

Table 1 Detection of cancer biomarkers and their reported sensitivity by various nanomaterials

\begin{tabular}{|c|c|c|c|c|c|}
\hline Sl. no. & Sensing materials & Techniques & Cells/cancer markers & Sensitivity/response & Ref. \\
\hline 1 & $\mathrm{TiO}_{2} / \mathrm{CNT}$ & $\mathrm{CV}$ & Leukemia & Not mentioned & 16 \\
\hline 2 & $\mathrm{Fe}_{3} \mathrm{O}_{4} / \mathrm{PB}$ & DPV & IgG & $5 \mathrm{nM}$ & 15 \\
\hline 3 & Nano-Au/NiHCF Nanoparticles & $\mathrm{CV}$ & CEA & $0.1 \mathrm{ng} \mathrm{mL}^{-1}$ & 14 \\
\hline 4 & $\mathrm{Au} /$ polylactide nanocomposites & EIS & Leukemia & 800 cells per mL & 20 \\
\hline 5 & Graphene/Au NPs & EIS & $\alpha$-Fetoprotein & $0.1 \mathrm{ng} \mathrm{mL} \mathrm{m}^{-1}$ & 34 \\
\hline 6 & Chitosan/Au NPs & Amperometry & CEA & $0.08 \mathrm{ng} \mathrm{mL}^{-1}$ & 46 \\
\hline 7 & $\mathrm{CdFe}_{2} \mathrm{O}_{4}-\mathrm{SiO}_{2}$ & Amperometry & IgG & $0.18 \mu \mathrm{g} \mathrm{mL}^{-1}$ & 12 \\
\hline 8 & PAMAM dendrimer & QCM & Human IgG & $7 \mathrm{nM}$ & 21 \\
\hline 9 & AuNPs/PAMAM & DPV & PSA & $0.5 \mathrm{ng} \mathrm{mL}{ }^{-1}$ & 22 \\
\hline
\end{tabular}




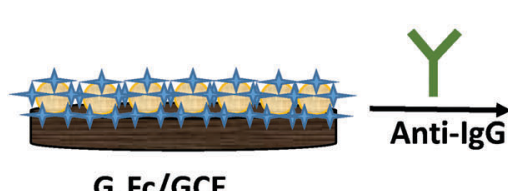

$\mathrm{G}_{2} \mathrm{Fc} / \mathrm{GCE}$

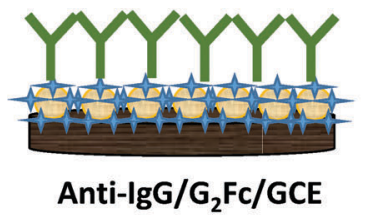

Anti-lgG/G $\mathbf{F c} / \mathrm{GCE}$
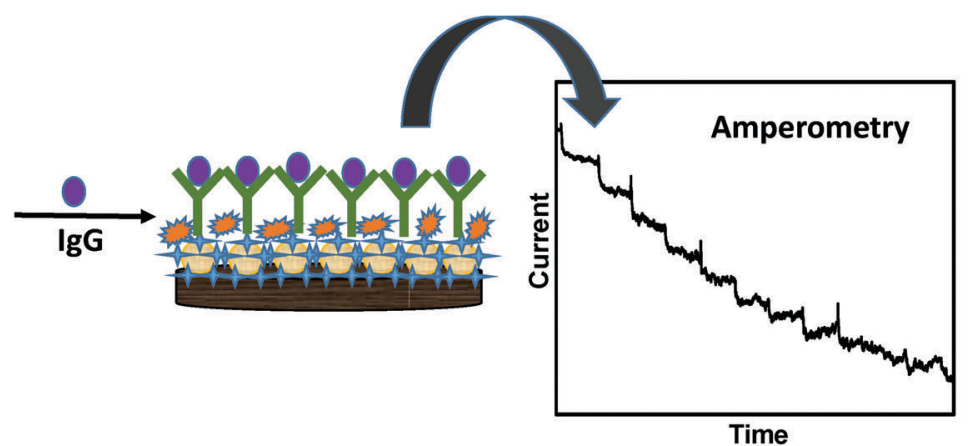
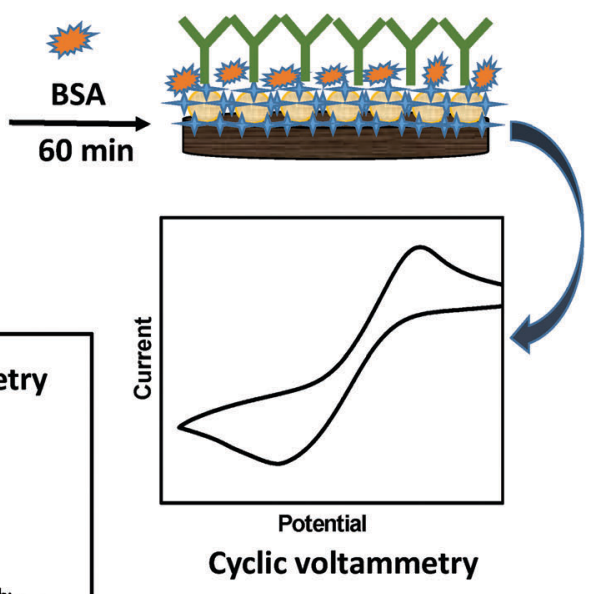

Scheme 1 Representation of the immunosensor based on ferrocenyl dendrimer $\left(\mathbf{G}_{2} \mathbf{F c}\right)$.

\section{Electrochemistry}

Measurements in an aqueous electrolyte. Cyclic voltammetry (CV) and amperometric experiments were performed on a $\mathrm{CH}$ Instrument Work Station 660D at ambient temperature. A 3-electrode system was used for the measurements with a bare and working glassy carbon electrode (GCE), a platinum wire as a counter electrode and an $\mathrm{Ag} / \mathrm{AgCl}$ reference electrode. The electrolytes were purged with $\mathrm{N}_{2}$ for at least $15 \mathrm{~min}$ for complete removal of $\mathrm{O}_{2}$. Purging with $\mathrm{N}_{2}$ was continued during measurements. The electrochemical response of the immunosensor towards IgG is based on the current response of the redox-active material (concentration: $1 \mathrm{mg} \mathbf{m L}$ of $\mathbf{G}_{\mathbf{2}} \mathbf{F c}$ ) after the formation of an antibody-antigen complex. ${ }^{29}$ Amperometry was carried out in an electrochemical cell containing $0.1 \mathrm{M}$ PBS and $1 \mathrm{mM} \mathrm{H}_{2} \mathrm{O}_{2}$ at $+0.3 \mathrm{~V}$ under constant stirring. The current-time profile was recorded after a steady state current was achieved.

Measurements in non-aqueous electrolyte. Electrochemical measurements of $\mathbf{G}_{2} \mathbf{F} \mathbf{c}\left(1.0 \mathrm{mmol} \mathrm{L}^{-1}\right.$ using $\left.\left[\mathrm{N}^{n} \mathrm{Bu}_{4}\right]\left[\mathrm{B}\left(\mathrm{C}_{6} \mathrm{~F}_{5}\right)_{4}\right]\right)$ in dichloromethane were performed in a dried, argon purged cell at $25{ }^{\circ} \mathrm{C}$ using a Radiometer Voltalab PGZ 100 electrochemical workstation interfaced with a personal computer. As supporting electrolyte $0.1 \mathrm{~mol} \mathrm{~L}^{-1}$ solutions of $\left[\mathrm{N}^{n} \mathrm{Bu}_{4}\right]\left[\mathrm{B}\left(\mathrm{C}_{6} \mathrm{~F}_{5}\right)_{4}\right]$ were used. A three-electrode cell containing a Pt auxiliary electrode, a glassy carbon working electrode (surface area $0.031 \mathrm{~cm}^{2}$ ) and an $\mathrm{Ag} / \mathrm{Ag}^{+}\left(0.01 \mathrm{mmol} \mathrm{L}^{-1}\left[\mathrm{AgNO}_{3}\right]\right)$ reference electrode fixed on a Luggin capillary were applied. The working electrode was pretreated by polishing on a Buehler microcloth first with $1 \mathrm{~mm}$ and then with a $\frac{1}{4} \mathrm{~mm}$ diamond paste. The reference electrode was constructed from a silver wire inserted into a $0.01 \mathrm{mmol} \mathrm{L}^{-1}$ $\left[\mathrm{AgNO}_{3}\right]$ and $0.1 \mathrm{~mol} \mathrm{~L}^{-1}\left[\mathrm{~N}^{n} \mathrm{Bu}_{4}\right]\left[\mathrm{B}\left(\mathrm{C}_{6} \mathrm{~F}_{5}\right)_{4}\right]$ acetonitrile solution in a Luggin capillary with a vycor tip. This Luggin capillary was inserted in a second Luggin capillary containing a $0.1 \mathrm{~mol} \mathrm{~L}^{-1}$ $\left[\mathrm{N}^{n} \mathrm{Bu}_{4}\right]\left[\mathrm{B}\left(\mathrm{C}_{6} \mathrm{~F}_{5}\right)_{4}\right]$ dichloromethane solution and a vycor tip. Under the same experimental conditions all reduction and oxidation potentials were reproducible within $5 \mathrm{mV}$. Experimental potentials were referenced against an $\mathrm{Ag} / \mathrm{Ag}^{+}$reference electrode but the presented results are referenced against ferrocene as an internal standard as required by IUPAC. ${ }^{30}$ To achieve this, each experiment was repeated in the presence of $1 \mathrm{mmol} \mathrm{L}^{-1}$ decamethylferrocene $\left(\mathrm{Fc}^{*}\right)$. Data were processed on a Microsoft Excel worksheet to set the formal reduction potentials of the $\mathrm{FcH} / \mathrm{FcH}^{+}$couple to $0.0 \mathrm{~V}$. Under our conditions the $\mathrm{Fc}^{*} / \mathrm{Fc}^{*+}$ couple was at $-619 \mathrm{mV}$ vs. $\mathrm{FcH} / \mathrm{FcH}^{+}, \Delta E_{\mathrm{p}}=60 \mathrm{mV}$, while the $\mathrm{FcH} / \mathrm{FcH}^{+}$couple itself was at $220 \mathrm{mV}$ vs. $\mathrm{Ag} / \mathrm{Ag}^{+}, \Delta E_{\mathrm{p}}=61 \mathrm{mV} .^{31}$

Anti-goat Immunoglobulin (anti-IgG), Immunoglobulin (IgG) and bovine serum albumin (BSA) were obtained from Sigma Aldrich and stored at $-20{ }^{\circ} \mathrm{C}$. Phosphate buffer saline (PBS, $0.1 \mathrm{M}, \mathrm{pH}$ 7.2) was used as electrolyte for the electrochemical measurements. Solvents and reagents were purchased, were of reagent grade and were used as such.

\section{Synthesis of the ferrocenyl end-grafted dendrimer $\left(\mathrm{G}_{2} \mathrm{Fc}\right)$}

The polyamidoamine (PAMAM)-based dendrimer 1 was modified $^{32,33}$ and functionalized peripherally by redox-active ferrocenyl units to form a new electro-active functional material, ferrocenyl end-grafted dendrimer $\left(\mathbf{G}_{\mathbf{2}} \mathbf{F} \mathbf{c}\right)$.

Synthesis. $100 \mathrm{mg}(0.15 \mathrm{mmol})$ of the $\mathrm{H}_{2} \mathrm{~N}$ end-grafted dendrimer $\mathrm{N}\left(\mathrm{CH}_{2} \mathrm{CH}_{2} \mathrm{C}(\mathrm{O}) \mathrm{NHCH}_{2} \mathrm{CH}_{2} \mathrm{NH}_{2}\right)\left(\mathrm{CH}_{2} \mathrm{CH}_{2} \mathrm{~N}\left(\mathrm{CH}_{2} \mathrm{CH}_{2}\right.\right.$ $\left.\left.\mathrm{C}(\mathrm{O}) \mathrm{NHCH}_{2} \mathrm{CH}_{2} \mathrm{NH}_{2}\right)_{2}\right)_{2}$ (1) (Fig. 1) and $206.6 \mathrm{mg}(0.9 \mathrm{mmol}$ ) of ferrocene carboxylic acid fluoride were dissolved in $100 \mathrm{~mL}$ of anhydrous dichloromethane and stirred for $5 \mathrm{~d}$ at $30{ }^{\circ} \mathrm{C}$. The reaction mixture was cooled to ambient temperature, the solvent was removed and the crude product was washed five times with acetonitrile (each $20 \mathrm{~mL}$ ) at $35^{\circ} \mathrm{C}$. After drying under vacuum, the title compound was obtained as an orange solid in 46\% (118 mg, $0.068 \mathrm{mmol}$ ) yield.

${ }^{1} \mathbf{H}$ NMR $\left(\mathbf{C D C l}_{3}\right) \cdot \delta=2.25-2.70\left(\mathrm{~m}, 28 \mathrm{H}, \mathrm{NCH}_{2} \mathrm{CH}_{2} \mathrm{C}(\mathrm{O})\right)$, $\left(\mathrm{NCH}_{2} \mathrm{CH}_{2} \mathrm{~N}\right), 3.48\left(\mathrm{~m}, 20 \mathrm{H}, \mathrm{HNCH}_{2} \mathrm{CH}_{2} \mathrm{NH}\right), 4.20(\mathrm{~s}, 25 \mathrm{H}$, $\left.H / \mathrm{C}_{5} \mathrm{H}_{5}\right), 4.33\left(\mathrm{~m}, 10 \mathrm{H}, H / \mathrm{C}_{5} \mathrm{H}_{4} \mathrm{C}(\mathrm{O})\right), 4.82\left(\mathrm{~m}, 10 \mathrm{H}, H / \mathrm{C}_{5} \mathrm{H}_{4} \mathrm{C}(\mathrm{O})\right)$, 7.30-7.55 (m, $5 \mathrm{H}, \mathrm{NH}), 7.80-8.30(\mathrm{~m}, 5 \mathrm{H}, \mathrm{NH}) \mathrm{ppm} .{ }^{13} \mathrm{C}\left\{{ }^{1} \mathrm{H}\right\}$ NMR $\left(\mathrm{CDCl}_{3}\right): \delta=34.1\left(\mathrm{CH}_{2} \mathrm{C}(\mathrm{O})\right), 39.5\left(\mathrm{HNCH}_{2} \mathrm{CH}_{2} \mathrm{NH}\right)$, 

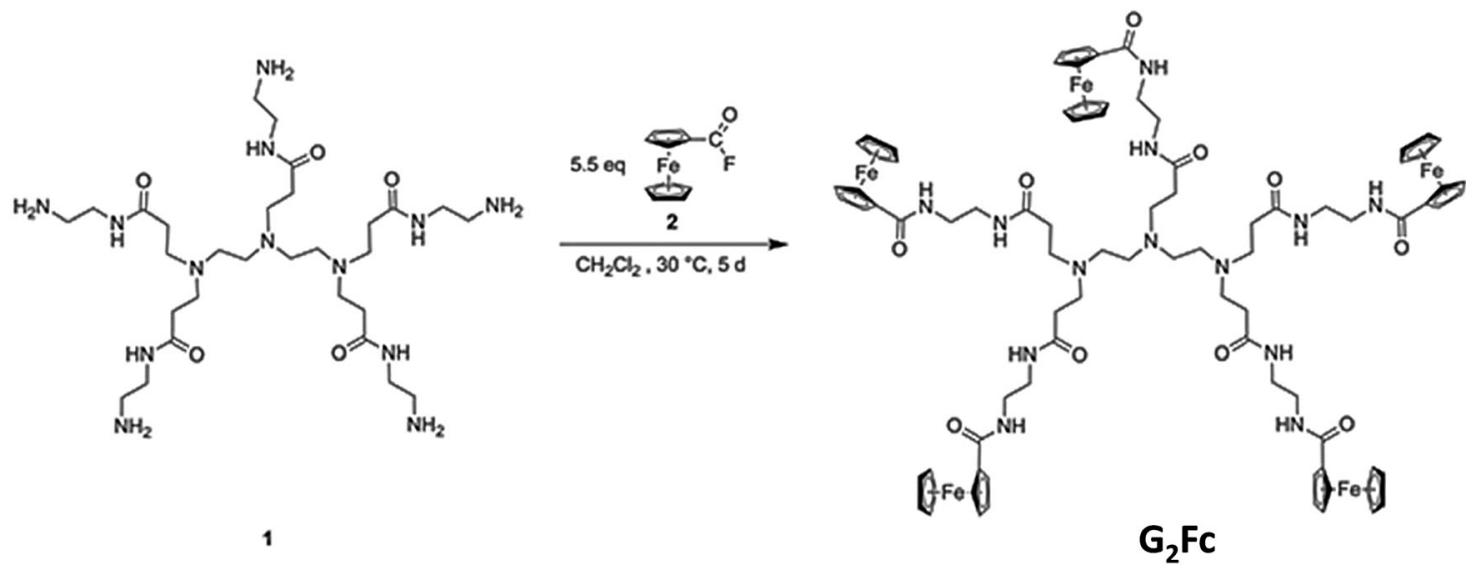

Fig. 1 Synthesis of ferrocenyl end-grafted dendrimers $G_{2} F c$.

$40.5\left(\mathrm{HNCH}_{2} \mathrm{CH}_{2} \mathrm{NH}\right)$, 50.5, $\left(\mathrm{NCH}_{2} \mathrm{CH}_{2} \mathrm{C}(\mathrm{O})\right), 51.5\left(\mathrm{NCH}_{2} \mathrm{CH}_{2} \mathrm{~N}\right)$, $68.6\left(\mathrm{C}_{\alpha} / C_{5} \mathrm{H}_{4} \mathrm{C}(\mathrm{O})\right), 70.0 \quad\left(\mathrm{C}_{5} \mathrm{H}_{5}\right), \quad 70.7 \quad\left(C_{\beta} / \mathrm{C}_{5} \mathrm{H}_{4} \mathrm{C}(\mathrm{O})\right), 75.9$ $\left(C_{\mathrm{i}} / \mathrm{C}_{5} \mathrm{H}_{4} \mathrm{C}(\mathrm{O})\right), 171.8(C(\mathrm{O})), 173.9(\mathrm{C}(\mathrm{O}))$. HRMS: $\mathrm{m} / z$ : calcd for $\mathrm{C}_{84} \mathrm{H}_{103} \mathrm{Fe}_{5} \mathrm{~N}_{13} \mathrm{O}_{10}$ : 867.7430, found 867.7487 $[\mathrm{M}+\mathrm{H}]^{2+}$; elemental analysis calcd (\%) for $\mathrm{C}_{84} \mathrm{H}_{103} \mathrm{Fe}_{5} \mathrm{~N}_{13} \mathrm{O}_{10}$ : C 58.18, $\mathrm{H}$ 5.99, N 10.50; found C 57.71, H 6.27 N 10.06.

\section{Fabrication of the immunosensor}

Ferrocenyl-functionalized dendrimers $\mathbf{G}_{\mathbf{2}} \mathbf{F} \mathbf{c}(\sim 10 \mu \mathrm{g})$ were drop-casted on the GCE and kept for drying under an ambient atmosphere for a few hours. Then, $10 \mu \mathrm{L}$ of $20 \mu \mathrm{g} \mathrm{mL}$ anti-goat IgG (0.1 M PBS, pH 7.2) was immobilized onto the $\mathbf{G}_{2} \mathbf{F c} / \mathrm{GCE}$. The electrode was incubated at $37{ }^{\circ} \mathrm{C}$ for $1 \mathrm{~h}$ and the unbound anti-goat IgG was washed away with PBS. The immobilized electrode was then incubated with $10 \mathrm{mg} \mathrm{mL}^{-1}$ of BSA for $60 \mathrm{~min}$ at $37{ }^{\circ} \mathrm{C}$ to avoid non-specific adsorption by blocking the active sites. ${ }^{34}$ The modified electrode was stored at $4{ }^{\circ} \mathrm{C}$ when not in use.

\section{Results and discussion}

$\mathbf{G}_{2} \mathbf{F c}$ dendrimers have been used as a redox responsive receptor system for immobilization of cancer biomarkers. The dendrimers can easily adsorb on the surfaces and hence the modification of electrodes is easier. The interaction of the active recognition units with the ferrocenyl end-grafted dendrimers enhanced the sensing ability of the system not only in solution but also when confined on the electrode surface.

\section{Electrochemical properties of ferrocenyl end-grafted dendrimers $\left(\mathbf{G}_{2} \mathbf{F c}\right)$}

The redox properties of $\mathbf{G}_{\mathbf{2}} \mathbf{F} \mathbf{c}$ have been monitored in aqueous and non-aqueous electrolytes.

In an aqueous electrolyte. The electrochemical behavior of a $\mathbf{G}_{2}$ Fc-modified GCE (=glassy carbon electrode) was investigated in an unstirred buffer solution ( $\mathrm{pH} 7.0,5 \mathrm{~mL}$ ) containing $0.1 \mathrm{M}$ $\mathrm{KCl}$ at room temperature under an inert atmosphere by cyclic voltammetry $(\mathbf{C V})$. The respective $\mathbf{G}_{2} \mathbf{F c}$ (ferrocenyl = Fc) showed the oxidation peak at $0.72 \mathrm{~V}$ and the reduction peak at $0.33 \mathrm{~V}$ in an aqueous electrolyte at a scan rate of $50 \mathrm{mV} \mathrm{s}^{-1}$. The ratio of the oxidation peak current-to-reduction peak current $\left(I_{\mathrm{pa}} / I_{\mathrm{pc}}\right)$ was calculated to be $\sim 1$. The peak current increased significantly with a shift in the anodic and cathodic peak towards lower potential, showing the promoting electro-active effect of the ferrocenyl end-grafted dendrimer electrode. The peak-topeak separation $\left(\Delta E_{\mathrm{p}}\right)$ of the Fc-dendrimer-coated GCE was calculated to be $390 \mathrm{mV}$. The single electrochemical process at $0.35 \mathrm{~V}(\mathrm{Ag} / \mathrm{AgCl})$ is attributed to the ferrocenyl moieties on the dendrimers. ${ }^{28}$

Subsequently, the influence of the potential scan rate on the cyclic voltammograms of the $\mathbf{G}_{\mathbf{2}} \mathbf{F} \mathbf{c} / \mathrm{GCE}$ electrodes was investigated (Fig. 2a). It was found that there is a shift in the peak potential along with an increase in the peak current as the scan rates increased from 10 to $200 \mathrm{mV} \mathrm{s}^{-1}$. The $\Delta E_{\mathrm{p}}$ values are about $400-500 \mathrm{mV}$ and remain fairly constant at lower scan rates, but increase with higher scan rates. This indicates that at a higher scan rate, the charge transfer is not sufficiently fast and the electrochemical reaction is basically charge-transfer controlled and not diffusion controlled (please note that we did not get linearity, when the peak current was plotted against the square root of the scan rate, Fig. 2b). This is indicative of a quasi-reversible system in which the current is controlled by both charge-transfer and mass-transfer. However, the system approaches reversibility as the scan rate increases.

Multiple successive scans were carried out to check the stability of the $\left(\mathbf{G}_{\mathbf{2}} \mathbf{F c}\right)$-modified GCE and it was found that the electro-activity is retained throughout the study. Moreover, the redox response was unchanged even after several days.

In a non-aqueous electrolyte. The cyclic voltammograms of $\mathbf{G}_{2} \mathbf{F c}$, measured in the presence of $\left[{ }^{n} \mathrm{Bu}_{4} \mathrm{~N}\right]\left[\mathrm{B}\left(\mathrm{C}_{6} \mathrm{~F}_{5}\right)_{4}\right]$ as electrolyte $^{35}$ at room temperature under an inert atmosphere, are shown in Fig. 3a. The application of $\left[{ }^{n} \mathrm{Bu}_{4} \mathrm{~N}\right]\left[\mathrm{B}\left(\mathrm{C}_{6} \mathrm{~F}_{5}\right)_{4}\right]$ as supporting electrolyte within electrochemical measurements has been demonstrated. ${ }^{36}$ The $\mathrm{CV}$ measurements were carried out at $20{ }^{\circ} \mathrm{C}$ and all potentials were referenced to the $\mathrm{FcH} / \mathrm{FcH}^{+}$ redox couple. ${ }^{37}$ The ferrocenyl groups were oxidized at the same 
(a)

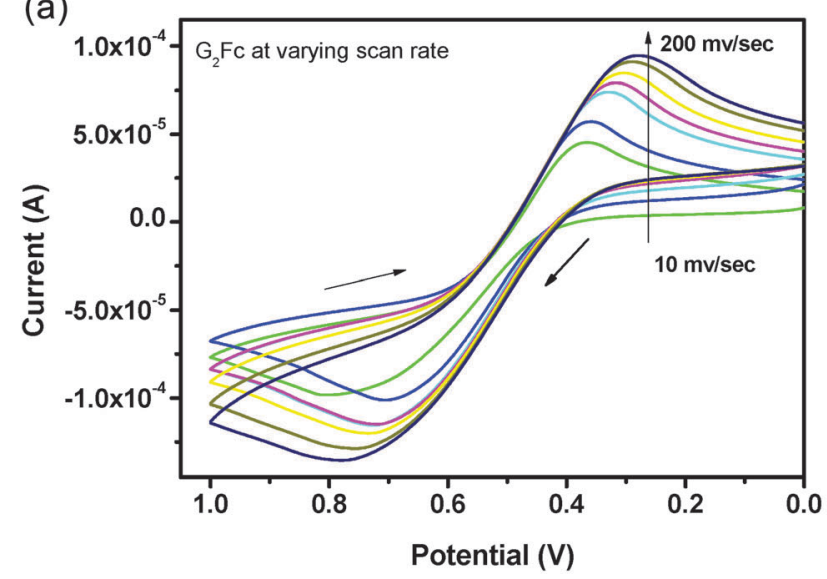

(b)

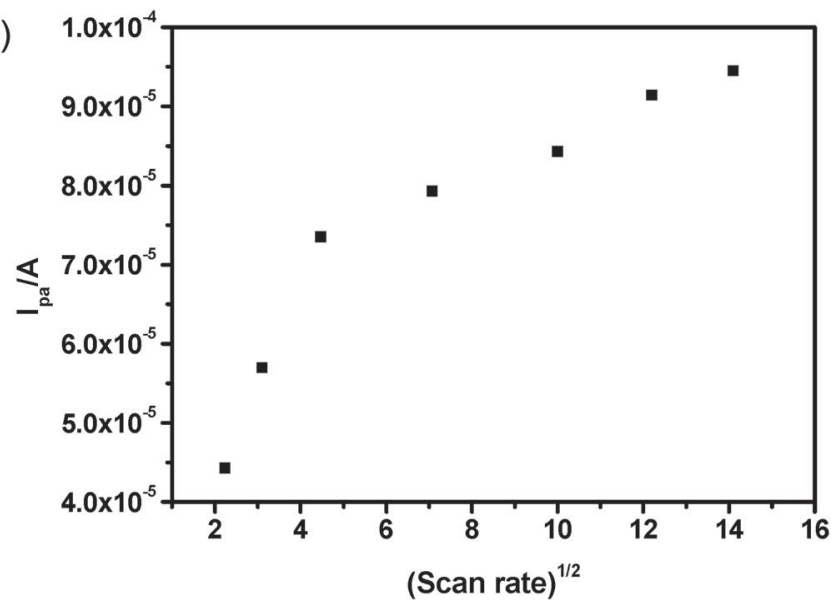

Fig. 2 (a) Cyclic voltammograms of $\mathrm{G}_{2} \mathrm{Fc}$ in an aqueous electrolyte at varying scan rates, (b) current vs. square root of the scan rate depicting a nonlinear response. CVs were measured at room temperature in PBS buffer $(\mathrm{pH} 7.0,5 \mathrm{~mL})$ containing $0.1 \mathrm{M} \mathrm{KCl}$.

potential showing one reversible redox event, with differences between the cathodic and the anodic peak potential $\Delta E_{\mathrm{p}}$ falling between 200 and $300 \mathrm{mV}$ depending on the scan rate (Fig. 3b). Peak currents are proportional to $\nu_{\frac{1}{2}}$, confirming the essentially reversible character of the ferrocenyl-based oxidation events. The electrostatic effect is sufficiently low because the terminal redox centers are located apart from each other and therefore a single $\mathrm{CV}$ wave is observed for all the five Fc redox centers. ${ }^{38}$

The potential shift $\left(\Delta E_{\mathrm{p}}\right)$ is higher in an aqueous electrolyte due to diffused electrostatic interactions and more H-bond interactions with the amido groups of the PAMAM dendrimers, respectively. ${ }^{39}$ Furthermore, the electrochemical (E) and chemical (C) reactions influence the shape of the voltammograms. In the present study, both electron-transfer kinetics and chemical reactions play an important role and based on the above results, it can be concluded that the oxidation of $\mathbf{G}_{2} \mathbf{F} \mathbf{c}$ proceeds via a $\mathrm{CE}$ mechanism. ${ }^{40}$ In both aqueous and non-aqueous electrolytes, the occurrence of a single redox process with simultaneous multi-electron transfer at the same potential indicates that the iron centers of the ferrocenyl units are non-interacting in the mixed-valent dendrimer. ${ }^{41}$

\section{Cyclic voltammetric characterization of the immunosensor}

Cyclic voltammetry was used to monitor the stepwise assembly of the electrochemical immunosensor for its potential application in biosensing. Cyclic voltammetric studies of the $\mathbf{G}_{2} \mathbf{F c}$ modified glassy carbon electrode in a $0.1 \mathrm{M}$ PBS solution of $\mathrm{pH}$ 7.2 showed a pair of well-defined redox peaks. The peak current decreased significantly with the immobilization of anti-goat IgG. After the immunosensor was blocked with BSA, a further decrease in the peak current was observed (Fig. 4). This may be due to the attachment of the protein BSA to the immunosensor. ${ }^{29}$ It was also found that the pH of the PBS solution affects the electrochemical immunosensor, due to denaturation of the BSA proteins. The current responses of the sensor were investigated at various $\mathrm{pH}$ values and the best current response was obtained at pH 7.2. Hence, for all further studies, PBS of pH 7.2 was used as optimum buffer solution.
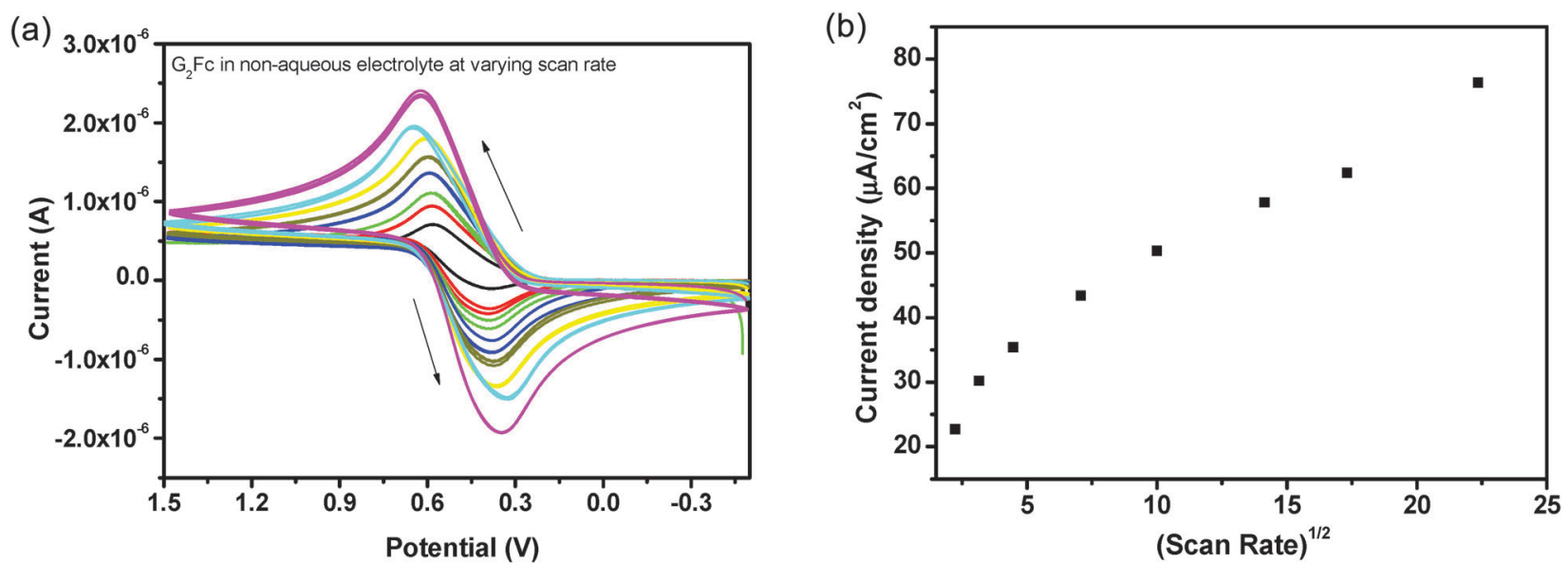

Fig. 3 (a) Cyclic voltammograms of $\mathrm{G}_{2} \mathrm{Fc}$ in the non-aqueous electrolyte at varying scan rates, (b) plot of current density versus square root of the scan rate depicting the non-linear response of the system; CVs were measured in $\left(1.0 \mathrm{mmol} \mathrm{L}{ }^{-1}\right.$ using $\left.\left[{ }^{n} \mathrm{Bu}_{4} \mathrm{~N}\right]\left[\mathrm{B}\left(\mathrm{C}_{6} \mathrm{~F}_{5}\right)_{4}\right]\right)$ in dichloromethane at room temperature. 


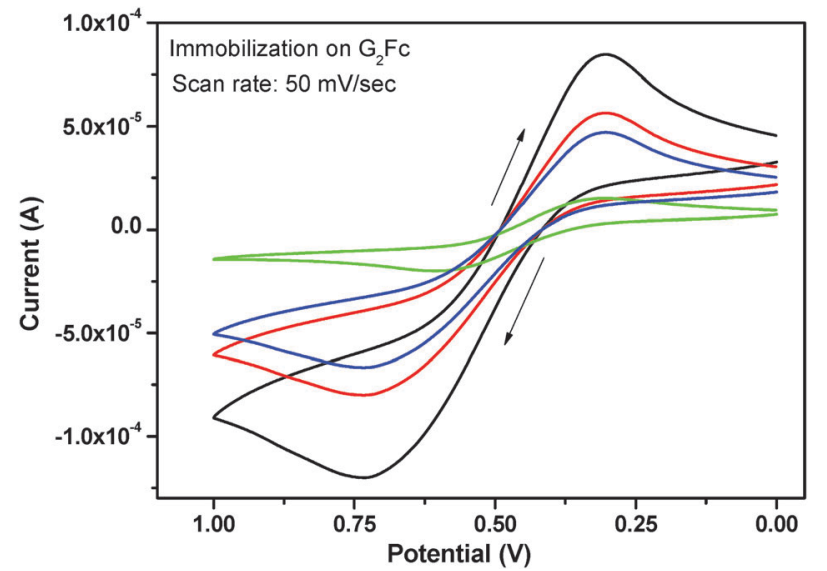

Fig. 4 Cyclic voltammograms of the $\mathrm{G}_{2} \mathrm{Fc}$ (black) recorded in $0.1 \mathrm{M}$ solution of PBS on immobilization with anti-lgG (red), BSA (blue) and IgG (green) at a scan rate of $50 \mathrm{mV} \mathrm{s}^{-1}$.

In addition, the effect of incubation time on the current response of the immunosensor was examined. It was found that the current response decreases with incubation time and levels within $60 \mathrm{~min}$. Therefore, $60 \mathrm{~min}$ was set as the optimum incubation time for the immobilization of BSA. Serum albumin is a weak polyacid and can be adsorbed on both positively and negatively charged surfaces depending on the $\mathrm{pH}$. At $\mathrm{pH}$ 7.2, BSA ( $\mathrm{pI}=4.8$ ) is negatively charged, while $\mathbf{G}_{2} \mathbf{F c}$ remains positively charged and this leads to the binding of BSA through electrostatic attractive strength. ${ }^{42}$

The concentration of the antibody plays a vital role in influencing the sensitivity of an immunoassay. Therefore, the effect of anti-IgG antibody concentration was studied with a series of concentrations ranging from $0.5 \mu \mathrm{g} \mathrm{mL} L^{-1}$ to $20 \mu \mathrm{g} \mathrm{mL}$ as a function of the current inhibition ratio, i.e., the relative change in the current response. It was found that with the increase in the concentration of the antibody up to $5 \mu \mathrm{g} \mathrm{mL} L^{-1}$, there was an increase in the current peak which then rapidly decreased as the antibody concentration was increased further. This may be ascribed to the molecular bonding between the antibody and the dendrimers which saturated at $5 \mu \mathrm{g} \mathrm{mL} \mathrm{m}^{-1}$. This led to the formation of a film that hindered the electron transmission towards the electrode surface thereby reducing the peak current. The maximum inhibition ratio was attained at a concentration of $5 \mu \mathrm{g} \mathrm{mL}{ }^{-1}$, which was therefore taken as the optimized concentration for further studies.

The incubation time of an antibody and an antigen is important for achieving a satisfactory sensitivity of an immunoassay. Therefore, antigen-antibody interaction was studied as a function of absorbance in a time scale from 10 to $30 \mathrm{~min}$. It was found that the intensity of the antibody-antigen reaction increased slightly with longer incubation time, and no significant difference was observed between the tests for $20 \mathrm{~min}$ and $30 \mathrm{~min}$. Hence, an incubation time of 20 min was taken for all the studies thereafter.

\section{Performances of the immunosensor}

The current signal of the fabricated immunosensor BSA/anti$\mathrm{IgG} / \mathbf{G}_{2} \mathbf{F c} / \mathrm{GCE}$ was further investigated with immobilizing IgG

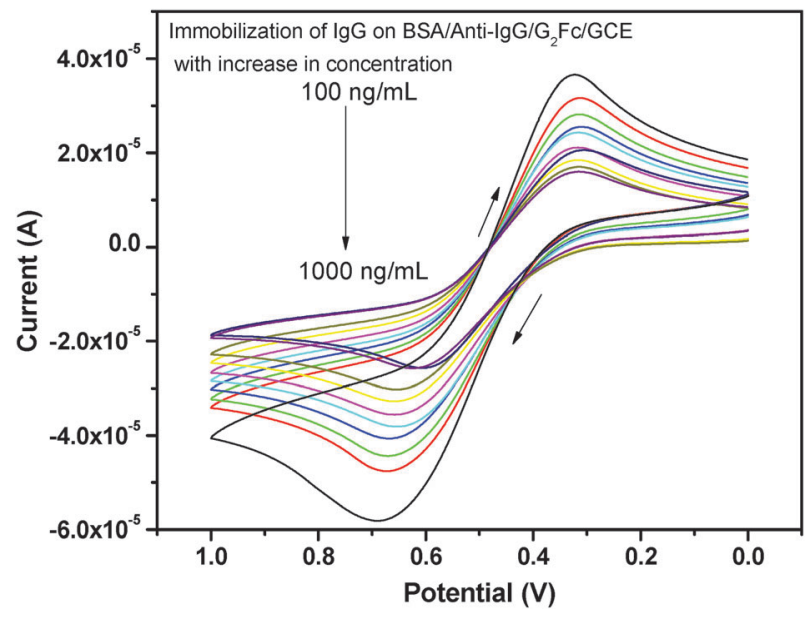

Fig. 5 Effect of the concentration of IgG on BSA/anti-IgG/G $\mathbf{2}$ Fc/GCE.

(Fig. 5). A significant decrease in the current was observed, which may be due to the formation of immune-conjugates that block the tunneling of mass and electron transfer. ${ }^{43}$ The current signal was found to be directly related to the amount of IgG captured on the electrode surface. With the increase in the concentration of IgG, there is an increase in the amount of immune-conjugates formed on the immunosensor, decreasing the peak current. A good linear relationship between the current response and the IgG concentration in the range 100 to $1000 \mathrm{ng} \mathrm{mL} \mathrm{mL}^{-1}$ with a correlation coefficient of 0.98664 was observed. This is associated with the electron flux involved in the redox reaction at the solution-immunosensor interface. The efficient and fast recognition of IgG may also be due to the electrostatic attraction forces between the carbonyl group of the ferrocenyl dendrimers and the amine groups of $\mathrm{IgG}^{44}$ The hydrophilicity of the dendrimer enhances the adsorption of IgG, prevents denaturation and also exposes the active sites for binding with the complementary IgG. ${ }^{45}$

A control experiment was carried out to determine the degree of non-specific binding of anti-IgG. The control electrode did not produce any considerable signal amperometrically (0.05-0.12 $\mu \mathrm{A})$, which showed that there was no significant non-specific adsorption of the antibody on the electrode surface. Further, the specificity of the immunosensor was also tested by incubating the BSA/anti-IgG/ $\mathbf{G}_{2} \mathbf{F c} /$ GCE probe in solutions containing $50 \mu \mathrm{g} \mathrm{mL} \mathrm{mL}^{-1}$ of BSA and $\alpha$-feto protein (AFP); however, no change in the peak current was observed. Therefore, it may be concluded that the current response of the BSA $/$ anti-IgG/ $/ \mathbf{G}_{2} \mathbf{F c} /$ GCE probe to the target antibody ( $\mathrm{Ig} G$ ) is due to a highly specific antigen-antibody interaction.

\section{Amperometric response to IgG}

The amperometric current response of BSA/anti-IgG/ $\mathbf{G}_{2} \mathbf{F c} / \mathrm{GCE}$ was recorded in $0.1 \mathrm{M}$ PBS at room temperature. The current response was monitored at $+0.3 \mathrm{~V}$ vs. $\mathrm{Ag} / \mathrm{AgCl}$. Under the optimum experimental conditions, the relationship between the current and the concentration of IgG was measured in a wide concentration range $\left(2-50 \mathrm{ng} \mathrm{mL}^{-1}\right)$. The data indicate 


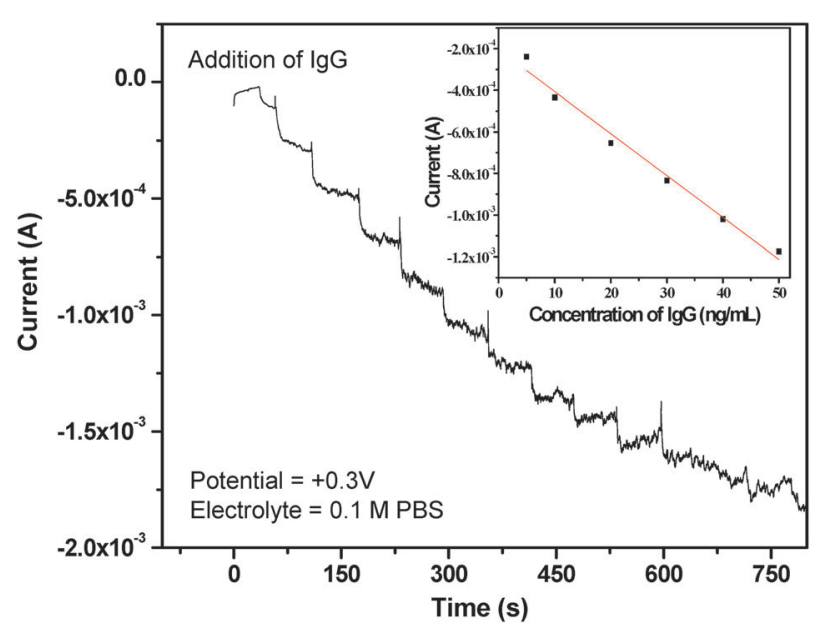

Fig. 6 Amperometric current-time response profile of IgG on BSA/ anti-lgG/ $\mathrm{G}_{2} \mathrm{Fc} / \mathrm{GCE}$. Inset shows the linearity of current response with increasing concentration of $\lg G$.

that the immunosensors are capable of estimating different concentrations of IgG and the amperometric response increased with the increase in the IgG concentration. As can be seen from Fig. 6, there is an immediate increase in the steady state current, which is due to the binding of IgG with the anti-IgG immobilized on $\mathbf{G}_{2} \mathbf{F c}$ at the electrode surface. The steady state currents (inset of Fig. 6) exhibited linearity in the range of $5-50 \mathrm{ng} \mathrm{mL}^{-1} \mathrm{IgG}$ and the linear dependencies of IgG yielded an equation of $I(\mu \mathrm{A})=$ $(-0.2046 \pm 0.00003)+(-0.02016 \pm 0.000001)[\mathrm{IgG}]\left(\mathrm{ng} \mathrm{mL}^{-1}\right)$ with a correlation coefficient of 0.9815 . The sensitivity of the developed immune-sensor was $0.020 \pm 0.00003 \mu \mathrm{A} \mathrm{mL} \mathrm{ng}^{-1}$ and the limit of detection was $\sim 2 \mathrm{ng} \mathrm{mL}^{-1}$, based on three measurements for the standard deviation ( $95 \%$ confidence level, signal-to-noise ratio $k=3$, number of repeated measurement $=3$ ). The results also show that the electrode retains its ability to exhibit linear amperometric responses over a period of time without denaturing the antibody.

The stability of the immunosensor was evaluated over a period of one month. A group of immunosensors was kept at $4{ }^{\circ} \mathrm{C}$ under identical conditions and was periodically checked for their amperometric response. No apparent change in the current response was observed.

As far as the working of an electrochemical immunosensor is concerned, immobilization of the sensing molecules on the electrode surface remains the crucial step. The immobilization process should be simple, fast and effective and efforts should be made to optimize the loading of the receptor molecules. Dendrimers on one hand provide porosity to the system and on the other hand provide functionalities to entrap the biomolecule. Tailoring of redox-active dendrimers provides enhanced electro-activity to the system and enlarges the sensor surface for binding the antibodies. This would result in a higher biosensor signal. ${ }^{46}$ It may be assumed that both electron transfer and diffusion contribute to the signal transformation between the electroactive dendrimers and the antibody.

\section{Conclusion}

Within this study a redox-active ferrocenyl dendrimer-modified glassy carbon electrode for the detection of cancer biomarkers is described. The electrochemical behavior of redox-active $\mathbf{G}_{2} \mathbf{F c}$ depends on the $\mathrm{pH}$ value and the type of electrolyte. The attachment of the biomarker and the binding events were studied by amperometry and cyclic voltammetry, respectively, with the results showing that the binding events result in a decrease in the exposed surface area giving rise to an increase in resistance and a lowering of the current intensity. The immunosensor requires very small amounts of the sample and exhibits shorter response times with good sensitivity towards IgG cancer biomarkers. The developed redox-active dendrimer-based immunosensor has the potential for further development into practical cancer diagnosis systems, which can be used in point-of-care quantitative tests for cancer biomarkers.

\section{Acknowledgements}

The authors are grateful to the Deutsche Forschungsgemeinschaft (DFG), Germany and the Department of Science and Technology (DST), India vide Reference No. SR/WOS-A/CS$45 / 2010$ for financial support.

\section{References}

1 S. Sengupta, Tetrahedron Lett., 2003, 44, 7281-7284.

2 S. M. Grayson and J. M. J. Fréchet, Chem. Rev., 2001, 101, 3819-3868.

3 C. Ornelas, J. Ruiz and D. Astruc, Organometallics, 2009, 28, 4431-4437.

4 C. Ornelas, J. Ruiz, C. Belin and D. Astruc, J. Am. Chem. Soc., 2009, 131, 590-601.

5 A. K. Diallo, J. C. Daran, F. Varret, J. Ruiz and D. Astruc, Angew. Chem., Int. Ed., 2009, 48, 3141-3145.

6 A. K. Diallo, C. Absalon, J. Ruiz and D. Astruc, J. Am. Chem. Soc., 2011, 133, 629-641.

7 D. Astruc, Nat. Chem., 2012, 4, 255-267.

8 J. F. Rusling, C. V. Kumar, J. S. Gutkinde and V. Patel, Analyst, 2010, 135, 2496-2511.

9 X. Qiu, X. Zhu, L. Zhang and Y. Mao, Cancer Res., 2003, 63, 6488-6495.

10 S. Chandra, N. Barola and D. Bahadur, Chem. Commun., 2011, 47, 11258-11260.

11 M. Yang, A. Javadi and S. Gong, Sens. Actuators, B, 2011, 155, 357-360.

12 Z. M. Liu, H. F. Yang, Y. F. Li, Y. L. Liu, G. L. Shen and R. Q. Yu, Sens. Actuators, B, 2006, 113, 956-962.

13 L. Qiao, X. Wang and X. Sun, Int. J. Electrochem. Sci., 2014, 9, 1399-1414.

14 Y. R. Yuan, R. Yuan, Y. Q. Chai, Y. Zhuo and X. M. Miao, J. Electroanal. Chem., 2009, 626, 6-13.

15 D. Tang, J. Tang, B. Su, H. Chen, J. Huang and G. Chen, Microchim. Acta, 2010, 171, 457-464. 
16 Q. Shen, S. K. You, S. G. Park, H. Jiang, D. Guo, B. Chen and X. Wang, Electroanalysis, 2008, 20, 2526-2530.

17 Y. Zhu, W. C. Alvin Koh and Y. B. Shim, Electroanalysis, 2010, 22, 2908-2914.

18 G. Liu, J. Wang, J. Kim, M. Jan and G. Collins, Anal. Chem., 2004, 76, 7126-7130.

19 R. Liang and W. J. Mu, Anal. Chim. Acta, 2006, 580, 128-135.

20 X. Wu, H. Jiang, J. Zheng, X. Wang, Z. Gu and C. Chen, J. Electroanal. Chem., 2011, 656, 174-178.

21 L. Svobodová, M. Śnejdárková, V. Polohová, I. Grman, P. Rybrá and T. Hianik, Electroanalysis, 2006, 18, 1943-1949.

22 B. Kavosia, A. Salimia, R. Hallaja and K. Amaniam, Biosens. Bioelectron., 2014, 52, 20-28.

23 (a) W. Chen, D. H. Xu, L. Q. Liu, C. F. Peng, Y. Y. Zhu, W. Ma, A. Bian, Z. Li and L. B. Wang, Anal. Chem., 2009, 81, 9194-9198; (b) S. Gupta, S. Huda, P. K. Kilpatrick and O. D. Velev, Anal. Chem., 2007, 79, 3810-3820; (c) G. S. Lai, F. Yan and H. X. Ju, Anal. Chem., 2009, 81, 9730-9736.

24 S. J. Kwon, E. Kim, H. Yang and J. Kwak, Analyst, 2006, 131, 402-406.

25 H. C. Yoon, M. Y. Hong and H. S. Kim, Anal. Chem., 2000, 72, 4420-4427.

26 S. Dietrich, A. Nicolai and H. Lang, J. Organomet. Chem., 2011, 696, 739-747.

27 T. H. Galow, J. Rodrigo, K. Cleary, G. Cooke and V. M. Rotello, J. Org. Chem., 1999, 64, 3745-3746.

28 E. R. de Jong, E. Manoury, J. C. Daran, C. O. Turrin, J. Chiffre, A. Sournia-Saquet, W. Knoll, J. P. Majoral and A. M. Caminade, J. Organomet. Chem., 2012, 718, 22-30.

29 A. Ray and S. Ghorai, Tetrahedron Lett., 2011, 52, 2980-2983.

30 G. Gritzner and J. Kuta, Pure Appl. Chem., 1984, 56, 461-466.

31 A. Nafady and W. E. Geiger, Organometallics, 2008, 27, 5624-5631.

32 S. Dietrich, S. Chandra, C. Georgi, S. Thomas, D. Makarov, S. Schulze, M. Hietschold, M. Albrecht, D. Bahadur and H. Lang, Mater. Chem. Phys., 2012, 132, 292-299.

33 S. Chandra, M. D. Patel, H. Lang and D. Bahadur, J. Power Sources, 2015, 280, 217-226.

34 K. J. Huang, D. J. Niu, J. Y. Sun and J. J. Zhu, J. Electroanal. Chem., 2011, 656, 72-77.

35 (a) W. E. Geiger and F. Barrière, Acc. Chem. Res., 2010, 43, 1030-1039; (b) F. Barrière and W. E. Geiger, J. Am. Chem. Soc., 2006, 128, 3980-3989; (c) F. Barrière, N. Camire,
W. E. Geiger, U. T. Mueller-Westerhoff and R. Sanders, J. Am. Chem. Soc., 2002, 124, 7262-7263.

36 (a) H. J. Gericke, N. I. Barnard, E. Erasmus, J. C. Swarts, M. J. Cook and M. A. S. Aquino, Inorg. Chim. Acta, 2010, 363, 2222-2232; (b) E. Fourie, J. C. Swarts, D. Lorcy and N. Bellec, Inorg. Chem., 2010, 49, 952-959; (c) J. C. Swarts, A. Nafady, J. H. Roudebush, S. Trupia and W. E. Geiger, Inorg. Chem., 2009, 48, 2156-2165; (d) D. Chong, J. Slote and W. E. Geiger, J. Electroanal. Chem., 2009, 630, 28-34; (e) V. N. Nemykin, G. T. Rohde, C. D. Barrett, R. G. Hadt, J. R. Sabin, G. Reina, P. Galloni and B. Floris, Inorg. Chem., 2010, 49, 7497-7509; $(f)$ V. N. Nemykin, G. T. Rohde, C. D. Barrett, R. G. Hadt, C. Bizzarri, P. Galloni, B. Floris, I. Nowik, R. H. Herber, A. G. Marrani, R. Zanoni and N. M. Loim, J. Am. Chem. Soc., 2009, 131, 14969-14978; $(g)$ A. Hildebrandt, S. W. Lehrich, D. Schaarschmidt, R. Jaeschke, K. Schreiter, S. Spange and H. Lang, Eur. J. Inorg. Chem., 2012, 1114-1121; (h) A. Hildebrandt, D. Schaarschmidt, R. Claus and H. Lang, Inorg. Chem., 2011, 50, 10623-10632; (i) A. Hildebrandt and H. Lang, Organometallics, 2013, 32, 5640-5653; $(j)$ U. Pfaff, A. Hildebrandt, D. Schaarschmidt, T. Rüffer, P. J. Low and H. Lang, Organometallics, 2013, 32, 6106-6117; ( $k$ ) A. Hildebrandt and H. Lang, Dalton Trans., 2011, 40, 11831-11837.

37 D. Miesel, A. Hildebrandt, M. Korb, P. J. Low and H. Lang, Organometallics, 2013, 32, 2993-3002.

38 D. Astruc, C. Ornelas and J. Ruiz, Acc. Chem. Res., 2008, 41, 841-856.

39 O. Reynes, T. Gulon, J. C. Moutet, G. Royal and E. SaintAman, J. Organomet. Chem., 2002, 656, 116-119.

40 C. A. Nijhuis, B. A. Boukamp, B. Jan Ravoo, J. Huskens and D. N. Reinhoudt, J. Phys. Chem. C, 2007, 111, 9799-9810.

41 M. Zamora, S. Herrero, J. Losada, I. Cuadrado, C. M. Casado and B. Alonso, Organometallics, 2007, 26, 2688-2693.

42 L. J. Feng, X. H. Zhang, D. M. Zhao and S. F. Wang, Sens. Actuators, B, 2011, 152, 88-93.

43 Y. Kong, J. Li, S. Wu, W. Cheng, R. K. Rana and J. J. Zhu, Sens. Actuators, B, 2013, 183, 187-193.

44 P. Thevenot, W. Hu and L. Tang, Curr. Top. Med. Chem., 2008, 8, 270-280.

45 D. Kim and A. E. Herr, Biomicrofluidics, 2013, 7, 041501.

46 Y. Liu, R. Yuan, Y. Chai, C. Hong, K. Liu and S. Guan, Microchim. Acta, 2009, 167, 217-224. 